\title{
Postoperative Benefit of Bone Anchored Hearing Systems: Behavioral Performance and Self-Reported Outcomes
}

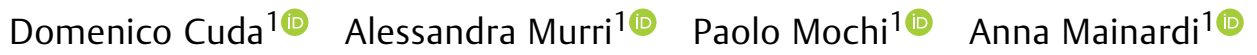 \\ ${ }^{1}$ Department of Otolaryngology, Guglielmo da Saliceto Hospital, \\ Piacenza, Italy \\ Address for correspondence Alessandra Murri, PhD, Department of \\ Otolaryngology, Guglielmo da Saliceto Hospital, Piacenza, 29100, \\ Int Arch Otorhinolaryngol 2022;26(3):e314-e320. \\ Italy (e-mail: alessandra_murri@libero.it).
}

\begin{abstract}
Introduction Bone anchored hearing solutions are a well-known option for patients with a conductive, mixed conductive-sensorineural hearing loss and those with singlesided deafness.

Objective The aim of the present study was to evaluate the Ponto bone-anchored hearing system in terms of behavioral performance and self-reported outcomes, by comparing unaided and aided performance (softband and abutment), as well as aided performance with the sound processor on softband (preoperatively) versus abutment (postoperatively).

Methods Fourteen adult bone-anchored candidates, with either a bilateral $(n=12)$ or unilateral $(n=2)$ conductive or mixed hearing loss, participated in the present study. Sound-field hearing thresholds were evaluated unaided and aided (softband and abutment). A speech-in-noise test was also performed unaided and aided for two spatial configurations (SON90; implanted side; SON90; nonimplanted side). The Glasgow Health Status Inventory and the Speech, Spatial and Quality of sound questionnaires were administered pre- and postsurgery to compare quality of life and perceived unaided and aided performance. Skin reaction (Holgers scores) was evaluated at 15 days, 6 weeks, and 10 weeks after surgery.

\section{Keywords}

- mixed hearing loss

- conductive hearing loss

- hearing aid

- health-related quality of life

Results Significant improvements postoperatively relative to unaided were obtained for sound-field thresholds at all tested frequencies. Additionally, sound-field thresholds were significantly improved with the sound processor on abutment relative to the softband at frequencies $>1 \mathrm{kHz}$. Improved performance postoperatively relative to unaided was also obtained in the speech-in-noise test and in self-reported outcomes. Conclusions Improvements in behavioral performance and self-reported outcomes were obtained with the sound processor mounted on abutment.
\end{abstract}

\section{Introduction}

Bone anchored hearing solutions (BAHS) are a well-known option for patients with a conductive or mixed conductive-

received

January 19, 2020 accepted after revision

August 26, 2020

published online

October 19, 2021
DOI https://doi.org/ 10.1055/s-0040-1718959. ISSN 1809-9777. sensorineural hearing loss and for patients with single-sided deafness (SSD). A BAHS consists of a titanium implant anchored to the mastoid, a skin-penetrating abutment, and a sound processor. ${ }^{1}$ The sound processor can also be used pre-

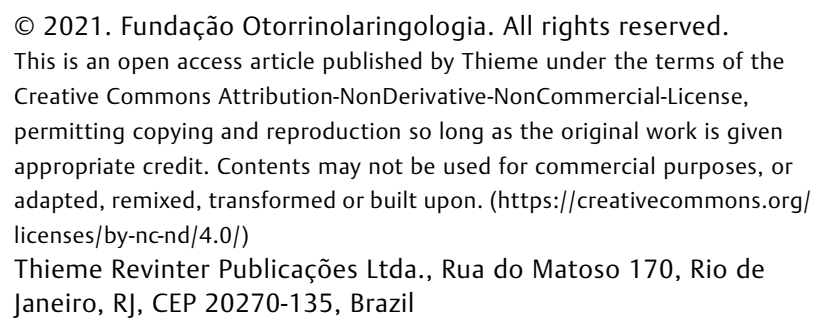


operatively on a softband or headband, and the patient can evaluate the benefit of the device prior to implantation., 2,3

It has been shown that the direct transmission of mechanical energy via the abutment (direct drive ${ }^{4}$ ) is more efficient than using a softband solution (skin drive ${ }^{4}$ ). In fact, when the sound processor is mounted on a softband, the sound is transmitted through the skin and subcutaneous tissues, which leads to an attenuation of 5 to $20 \mathrm{~dB}$ at mid and high frequencies. $^{5,6}$ The loss of energy that occurs with the skin-drive solution can be compensated when programming the device with the fitting software. However, increasing the gain to compensate for the transmission loss leads to a reduced headroom in the device. This means that saturation artifacts may be introduced in the signal already at medium input levels, resulting in a decreased sound quality with the softband solution. ${ }^{6}$ Hence, the use of direct-drive solutions, such as a sound processor connected to an abutment, leads to increased sound quality and amplification options.

A few studies have compared the performance of the patients with the sound processor mounted on softband or testband versus abutment. ${ }^{5-7}$ In the light of the new technological developments in surgical techniques and sound processors, it was of interest here to provide further evidence for the benefit of treatment with BAHS. The aim of the present study was to evaluate behavioral performance and selfreported outcomes preoperatively (unaided and with the device on softband) and postoperatively with the device mounted on abutment in traditional candidates treated at a tertiary referral center. Different outcome measures were performed pre- and postoperatively on adult BAHS candidates: sound-field hearing thresholds, speech-in-noise performance in a spatial setup, and two questionnaires (Glasgow Health
Status Inventory [GHSI, Italian version] and the Speech, Spatial and Qualities of hearing scale [SSQ, Italian version]).

\section{Materials and Methods}

\section{Patients}

Fourteen adult BAHS candidates ( 3 males, 11 females) participated in the study. The average age was of 57 years old (minmax: 22-78 years old); see - Table 1). Twelve patients had bilateral conductive or mixed hearing loss, and 2 patients unilateral conductive or mixed hearing loss (patients 7 and 13; normal or near-normal hearing ear: pure tone average [PTA] AC $\leq 25 \mathrm{~dB} \mathrm{HL}$ ). The PTA of the audiometric thresholds (air and bone conduction; AC and BC) is presented in - Table 1 .

\section{Devices and Specifications}

All patients were fitted with a sound processor from the Ponto Plus family (Oticon Medical AB, Askim, Sweden), which was released in December 2013. Six patients were fitted with the Ponto Plus Power device and the remaining patients were fitted with the Ponto Plus. All patients were implanted with the $4 \mathrm{~mm}$ Wide Ponto implant.

\section{Procedure}

The present study was conducted as part of routine clinical practice and consisted of five visits, as listed in - Table 2 . The present research received the approval of the ethics committee (number: 361/2018/DISP/AUSLPC). All procedures contributing to this work comply with the ethical standards of the relevant national and institutional guidelines on human experimentation and with the Helsinki Declaration of 1975 , as revised in 2008.

Table 1 Patients characteristics and PTA (average hearing threshold at 0.5, 1, 2, $4 \mathrm{kHz}$ )

\begin{tabular}{|c|c|c|c|c|c|c|c|}
\hline Patient & $\begin{array}{l}\text { Age } \\
\text { [years old] }\end{array}$ & $\begin{array}{l}\text { Hearing } \\
\text { loss }\end{array}$ & $\begin{array}{l}\text { Implanted } \\
\text { ear }\end{array}$ & $\begin{array}{l}\text { PTA AC L } \\
{[\mathrm{dB} \mathrm{HL}]}\end{array}$ & $\begin{array}{l}\text { PTA BC L } \\
\text { [dB HL] }\end{array}$ & $\begin{array}{l}\text { PTA AC R } \\
\text { [dB HL] }\end{array}$ & $\begin{array}{l}\text { PTA BC R } \\
\text { [dB HL] }\end{array}$ \\
\hline 1 & 61 & Bilateral & $R$ & 86.3 & 52.5 & 86.3 & 43.8 \\
\hline 2 & 60 & Bilateral & $R$ & 52.5 & 45.0 & 50.0 & 38.8 \\
\hline 3 & 78 & Bilateral & $\mathrm{L}$ & 76.3 & 46.3 & 95.0 & 58.8 \\
\hline 4 & 71 & Bilateral & $R$ & 88.8 & 55.0 & 50.0 & 33.8 \\
\hline 5 & 62 & Bilateral & $R$ & 50.0 & 42.5 & 63.8 & 43.8 \\
\hline 6 & 67 & Bilateral & $\bar{L}$ & 58.8 & 30.0 & 63.8 & 37.5 \\
\hline 7 & 55 & Unilateral & $R$ & 25.0 & 20.0 & 72.5 & 38.8 \\
\hline 8 & 49 & Bilateral & $R$ & 57.5 & 22.5 & 48.8 & 27.5 \\
\hline 9 & 55 & Bilateral & $\mathrm{L}$ & 36.3 & 15.0 & 45.0 & 16.3 \\
\hline 10 & 44 & Bilateral & $\mathrm{L}$ & 63.8 & 17.5 & 26.3 & 21.3 \\
\hline 11 & 22 & Unilateral & $R$ & 10.0 & 5.0 & 75.0 & 17.5 \\
\hline 12 & 64 & Bilateral & $R$ & 47.5 & 31.3 & 88.8 & 33.8 \\
\hline 13 & 52 & Bilateral & $R$ & 45.0 & 27.5 & 48.8 & 23.8 \\
\hline 14 & 58 & Bilateral & $R$ & 68.8 & 28.8 & 40.0 & 15.0 \\
\hline
\end{tabular}

(NR: no response; *average threshold at $0.5,1,2 \mathrm{kHz}$ - no response registered at $4 \mathrm{kHz}$; ${ }^{* *}$ threshold at $500 \mathrm{~Hz}$ - no response registered at $1,2,4 \mathrm{kHz}$ ). Abbreviations: PTA, pure tone average; AC, air conduction; BC, bone conduction. 
Table 2 Test flow consisting of one visit before surgery and three follow-up visits after surgery

\begin{tabular}{|c|c|c|c|c|c|c|}
\hline Visit & \multicolumn{2}{|l|}{1} & 2 & 3 & 4 & 5 \\
\hline & $\begin{array}{l}\text { Baseline } \\
\text { (unaided) }\end{array}$ & Softband & \multirow[t]{9}{*}{ Surgery } & $\begin{array}{l}\text { Surgical } \\
\text { follow-up }\end{array}$ & $\begin{array}{l}\text { Fitting of processor } \\
\text { on abutment. }\end{array}$ & $\begin{array}{l}\text { Fitting } \\
\text { follow-up }\end{array}$ \\
\hline Timeline & & & & $\begin{array}{l}15 \text { days after } \\
\text { surgery }\end{array}$ & $\begin{array}{l}6 \text { weeks after } \\
\text { surgery }\end{array}$ & $\begin{array}{l}4 \text { weeks after } \\
\text { visit } 4\end{array}$ \\
\hline$A C$ and $B C$ audiometry & $x$ & & & & & \\
\hline BC in situ & & $x$ & & & $x$ & \\
\hline Sound-field audiometry & $x$ & $x$ & & & & $x$ \\
\hline Speech-in-noise & $x$ & & & & & $x$ \\
\hline SSQ questionnaire & $x$ & & & & & $x$ \\
\hline GHSI questionnaire & $x$ & & & & & $x$ \\
\hline Holgers scores & & & & $x$ & $x$ & $x$ \\
\hline
\end{tabular}

Abbreviations: AC, Air conduction; BC, Bone conduction; GHSI: Glasgow Health Status Inventory questionnaire; SSQ: Speech, Spatial and Qualities questionnaire.

\section{Outcome Measures}

Sound-Field Thresholds (Aided and Unaided)

Sound-field thresholds were measured unaided and aided (softband and abutment) using warble tones presented via a loudspeaker located at 1 meter in front of the subject. Patients with unilateral hearing loss had their nonaided ear blocked by means of an earplug to make the sound field test sensitive toward the fitted sound processor. Additionally, patient 12 had also the right ear blocked due to the low AC threshold on the nonfitted side.

\section{Speech-in-noise Performance}

Speech intelligibility in noise was measured with the standardized Italian matrix sentence test. ${ }^{8}$ The test is run adaptively to estimate the signal to noise ratio (SNR) to reach 50\% correct speech intelligibility. The speech level was fixed at $65 \mathrm{~dB}$ SPL, while the noise level varied in $2 \mathrm{~dB}$ steps. Two loudspeaker configurations were used: speech from the front loudspeaker and noise from the implanted side $\left(\mathrm{S}_{0} \mathrm{~N}_{90}\right.$, I $)$; speech from the front loudspeaker and noise from the nonimplanted side $\left(\mathrm{S}_{0} \mathrm{~N}_{90}\right.$, NI $)$.

The test was performed unaided and with the sound processor mounted on abutment. In case of unilateral hearing loss, the nonaided ear was not blocked, as the speech test was designed to reflect a realistic sound scenario, where the sensitivity to the fitted devices was obtained by performing two different spatial setups. In the aided conditions, the directionality setting was either omnidirectional or full directional.

\section{Subjective Outcomes}

Two questionnaires were administered in the present study. The $\mathrm{GHSI}^{9}$ was provided to clarify the improvement in health-related quality of life with the sound processor fitted on abutment relative to unaided. The SSQ ${ }^{10}$ with 49 items, Italian version, was provided to clarify the perceived performance with the sound processor pre- and postoperatively (unaided versus abutment).

\section{Surgical Outcomes}

The minimally invasive Ponto surgery (MIPS) was used for 7 patients, and the linear incision technique for 10 patients. No complications were observed during surgery. Surgical outcomes, in terms of skin reactions (Holgers scores ${ }^{11}$ ) and eventual postoperative complications, were reported for each patient at the three follow-up visits after surgery.

\section{Statistical Analysis}

Mixed-linear models were implemented in R-studio (Boston, MA, USA) using the statistical package lmerTest. ${ }^{12}$ T-tests were performed in Matlab (MathWorks, Natick, MA, USA).

\section{Results}

\section{BC-in situ Thresholds}

-Fig. 1 shows the mean BC hearing thresholds, as measured in-situ via the sound processor, mounted on either the

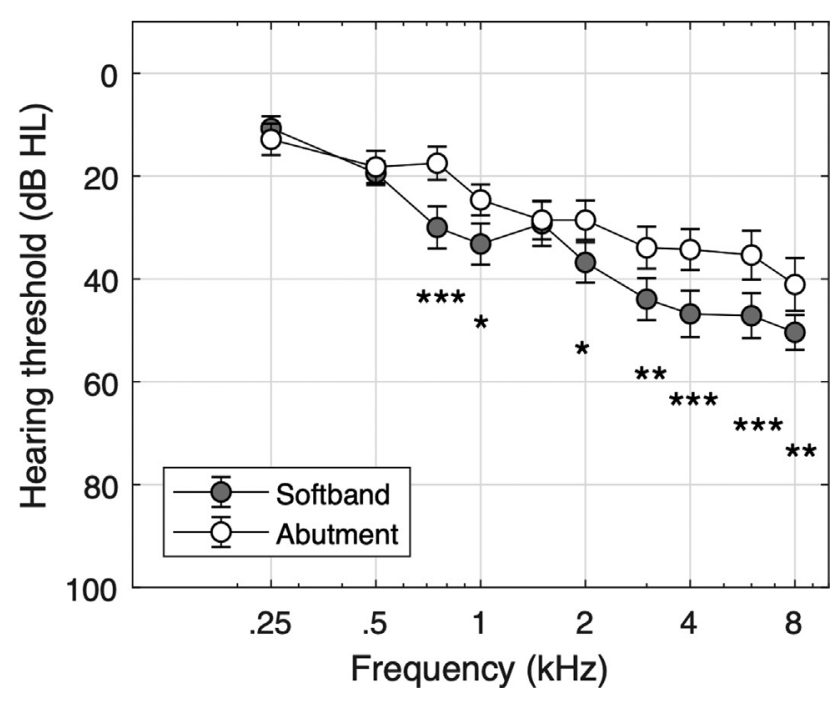

Fig. 1 Mean bone conduction in-situ thresholds for 14 patients (bilateral and unilateral patients), as measured via the sound processor mounted on either softband or abutment. Error bars depict the standard error of the mean. Significant differences between softband and abutment are indicated by: ${ }^{*} p<0.05 ;{ }^{* *} p<0.01 ;{ }^{* * *} p<0.001$. 
softband (preoperatively) or the abutment (postoperatively). The thresholds depict the average BC hearing threshold for all 14 bilateral and unilateral patients (SSD patients were not included in the mean).

The mixed-model analysis of variance (ANOVA) revealed a significant effect of condition $[\mathrm{F}(1.246)=48.9 ; p<0.0001]$, frequency $[\mathrm{F}(9.246)=42.2 ; p<0.0001]$, as well as the interaction between condition and frequency $[F(9.246)=2.6$; $p=0.006]$. The post-hoc analysis showed that the difference between softband and abutment was significant at the following frequencies: $750 \mathrm{~Hz}(p=0.0003), 1 \mathrm{kHz}(p=0.012), 2 \mathrm{kHz}$ $(p=0.015), \quad 3 \mathrm{kHz} \quad(p=0.003), 4 \mathrm{kHz} \quad(p=0.0003), 6 \mathrm{kHz}$ $(p=0.0005)$, and $8 \mathrm{kHz}(p=0.0012)$. The hearing thresholds did not differ at $250 \mathrm{~Hz}(p=0.525), 500 \mathrm{~Hz}(p=0.719)$, and $1.5 \mathrm{kHz}(p=0.832)$. Thus, sound transmission was significantly improved with the abutment relative to the softband at mostly mid and high frequencies. The average difference between softband and abutment was of $10.6 \mathrm{~dB}$ at frequencies between 2 and $8 \mathrm{kHz}$.

\section{Sound-field Thresholds}

- Fig. 2a shows the mean sound-field thresholds, as measured unaided and aided with the sound processor mounted on either softband (preoperatively) or abutment (postoperatively). The thresholds are the average of 12 patients; 11 with bilateral hearing loss (HL) and one with unilateral $\mathrm{HL}$ (with the normal-hearing ear blocked). One bilateral patient (patient 14 ) with a highly asymmetrical hearing loss ( $41 \mathrm{~dB}$ difference in PTA AC; $30 \mathrm{~dB} \mathrm{HL}$ at 1 and $2 \mathrm{kHz}$ ) was removed from the average data, since the AC of the nonimplanted ear was the main contributor to the obtained thresholds.

The mixed-model ANOVA revealed a significant effect of condition $(\mathrm{F}[2.22]=48.17 ; \quad p<0.0001)$, frequency $(\mathrm{F}$ $[7.77]=4.77 ; p=0.0002$ ), and a significant interaction of condition and frequency $(\mathrm{F}(14.154)=4.25 ; p<0.0001)$. The post-hoc analysis showed a significant difference between the thresholds measured unaided and aided with the sound processor on abutment at all frequencies ( $p<0.0001$; after Tukey correction for multiple comparisons). The difference between unaided and softband was significant at all frequencies $<8 \mathrm{kHz}(250,500,1,000 \mathrm{~Hz}: p<0.0001 ; 2 \mathrm{kHz}$ : $p=0.0006 ; 3 \mathrm{kHz}: p=0.0004 ; 4 \mathrm{kHz}: p=0.037 ; 6 \mathrm{kHz}$ : $p=0.027)$. The difference between softband and abutment was significant at frequencies above $1 \mathrm{kHz}(2 \mathrm{kHz}: p=0.027$; $3 \mathrm{kHz}: p<0.0001 ; 4 \mathrm{kHz}: p=0.0003 ; 6 \mathrm{kHz}: p<0.0001$; $8 \mathrm{kHz}: p=0.0004)$.

The average sound-field thresholds at $0.5,1,2,4 \mathrm{kHz}$ (referred to as PTA4) was of $59.3 \mathrm{~dB} \mathrm{HL}, 41.8 \mathrm{~dB} \mathrm{HL}$, and $34.2 \mathrm{~dB} \mathrm{HL}$, in the unaided, softband, and abutment conditions, respectively (for unilateral and bilateral patients; see - Table 3). Planned comparisons with paired $t$-tests on the PTA4 confirmed a significant difference between softband and abutment $(p=0.030)$, unaided and softband $(p=0.0002)$, unaided and abutment $(p<0.0001)$.

- Fig. $2 \mathbf{b}$ shows the remaining air-bone gap, calculated as the difference between the aided sound field threshold and the BC threshold, for abutment (open symbols) and softband (closed gray symbols). The remaining air-bone gap was significantly greater than zero at $500 \mathrm{~Hz}(p=0.014), 1 \mathrm{kHz}$ $(p=0.012), 3 \mathrm{kHz}(p<0.001)$, and $4 \mathrm{kHz}(p<0.0001)$ with the softband, and only at $500 \mathrm{~Hz}(p=0.021)$ with the abutment. The mean remaining air-bone gap was of $11.3 \mathrm{~dB}$ with softband and of $1.8 \mathrm{~dB}$ with abutment (average gap across all tested frequencies between $500 \mathrm{~Hz}$ and $4 \mathrm{kHz}$ ).

\section{Glasgow Health Status Inventory Questionnaire}

-Fig. 3 depicts the health-related quality of life scores (total, general, social, and physical), averaged across all 14 patients, as obtained from the GHSI questionnaire unaided and aided (abutment). The total average scores were of $42.8 \%$ (standard
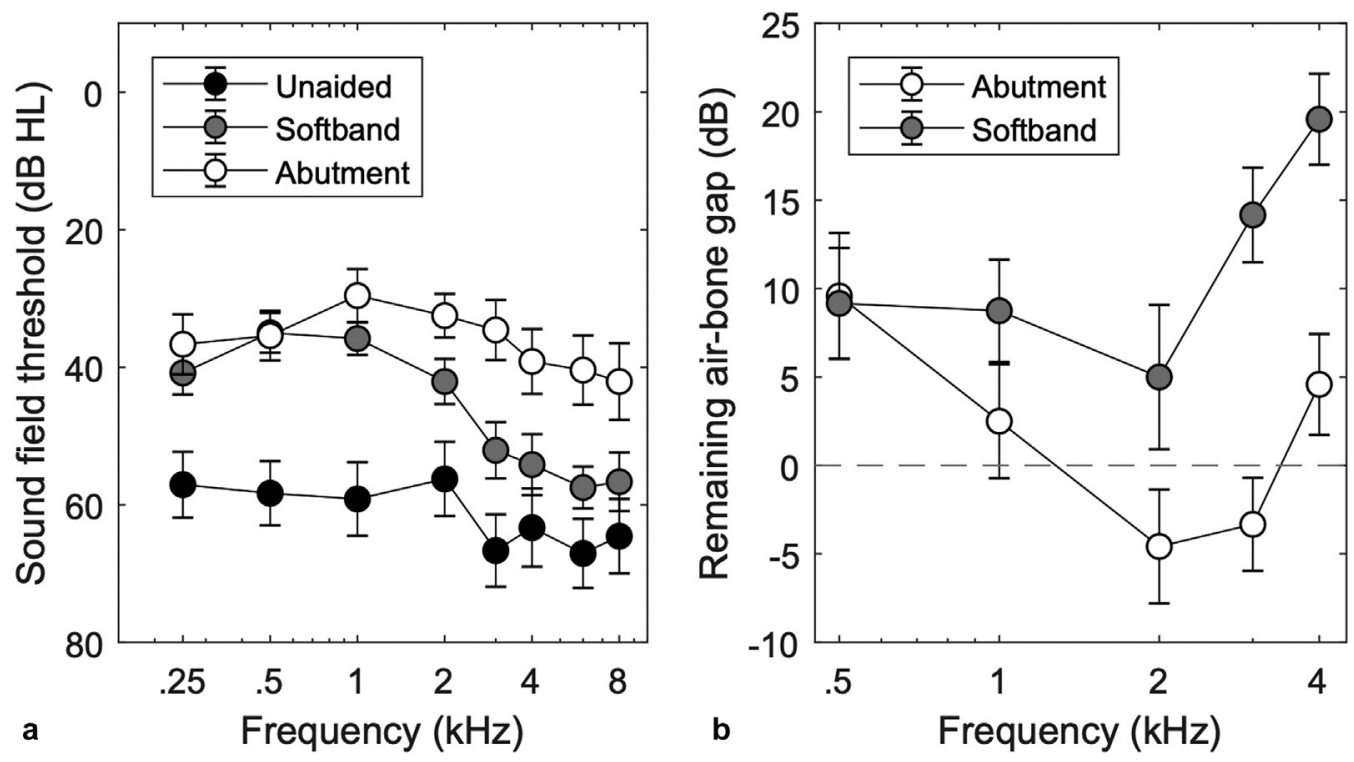

Fig. 2 (a) Mean sound-field thresholds for 12 patients (bilateral and unilateral patients with non-implanted ear blocked), as measured unaided and aided (softband and abutment). Error bars depict the standard error of the mean. (b) Mean remaining air-bone gap, calculated as the difference between the aided sound field thresholds and the bone conduction thresholds, for the same patients as in left panel. Error bars depict the standard error of the mean. 
Table 3 Average BC thresholds for the implanted ear, unaided and aided sound-field thresholds (PTA4 at 0.5, 1, 2, 4 kHz and standard deviation)

\begin{tabular}{|l|l|l|l|l|}
\hline Patients & $\begin{array}{l}\text { PTA4 BC } \\
\text { Implanted ear }[\mathrm{dB} \text { HL] }\end{array}$ & $\begin{array}{l}\text { PTA4 Unaided } \\
{[\mathrm{dB} \text { HL] }}\end{array}$ & $\begin{array}{l}\text { PTA4 Aided } \\
\text { Softband } \\
{[\mathrm{dB} \text { HL }]}\end{array}$ & $\begin{array}{l}\text { PTA4 Aided Abutment } \\
{[\mathrm{dB} \text { HL] }}\end{array}$ \\
\hline $\begin{array}{l}\text { Bilateral and Unilateral } \\
(n=14)\end{array}$ & $31.1 \pm 11.5$ & $59.3 \pm 15.0$ & $41.8 \pm 8.2$ & $34.2 \pm 12.5$ \\
\hline
\end{tabular}

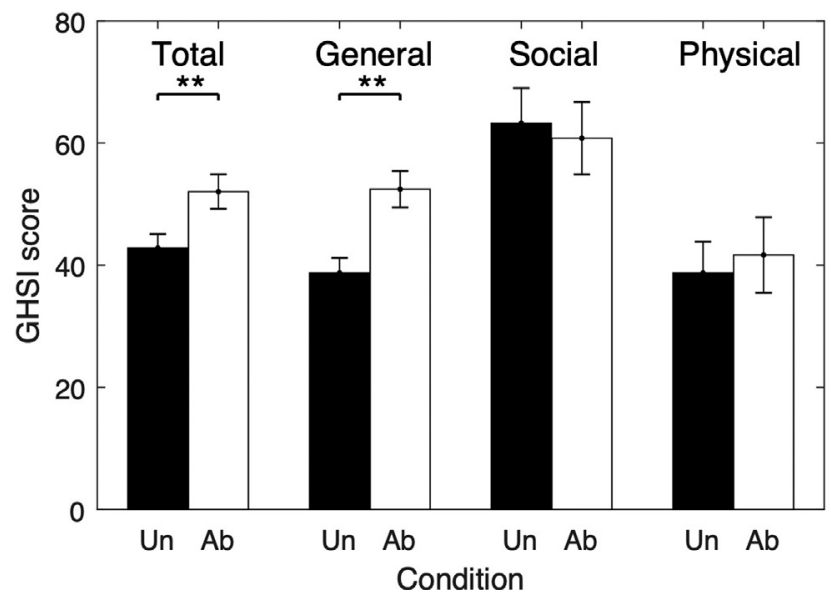

Fig. 3 Glasgow Health Status Inventory questionnaire mean scores ( $n=14$ patients), preoperatively (unaided, Un) versus postoperatively (sound processor mounted on abutment, Ab). Error bars depict the standard error of the mean. Significant differences between unaided and abutment are indicated by ${ }^{* *}(p<0.01)$.

deviation $[S D]=9.1 \%)$ and $52.1 \%(S D=12.4 \%)$, unaided and aided, respectively. Wilcoxon matched paired tests revealed that the abutment led to significantly higher scores than the unaided condition in the total $(p=0.006)$ and general $(p=0.007)$ domains (critical $p$-value $=0.0125$ after Bonferroni correction by $n=4$ comparisons).

\section{Speech, Spatial and Qualities Questionnaire}

-Fig. 4 depicts the mean scores of the SSQ questionnaire for the three subscales: Speech, Spatial, and Qualities of hearing. The mixed-model ANOVA revealed a significant effect of condition (Unaided versus Abutment: F [1.80] $=31.30$; $p<0.0001)$ and of subscale $(\mathrm{F}[2,80]=11.65 ; p<0.0001)$ on the SSQ scores. The interaction of condition and subscale was not significant $(F[2.80]=0.18 ; p=0.834)$. Hence, the perceived performance with the sound processor connected to the abutment was significantly higher across subscales $(p<0.0001)$. The post-hoc analysis showed that the scores in the subscale Quality were significantly higher than the scores in the other two subscales (Speech versus Quality: $p=0.007$; Spatial versus Quality: $p<0.0001$; Tukey correction for multiple comparisons), while the scores in the Speech and Spatial subscales were not significantly different $(p=0.238$; Tukey correction for multiple comparisons).

\section{Speech-in-noise Performance}

Nine patients (bilateral and unilateral) completed all test conditions of the speech-in-noise test. - Fig. 5 depicts the

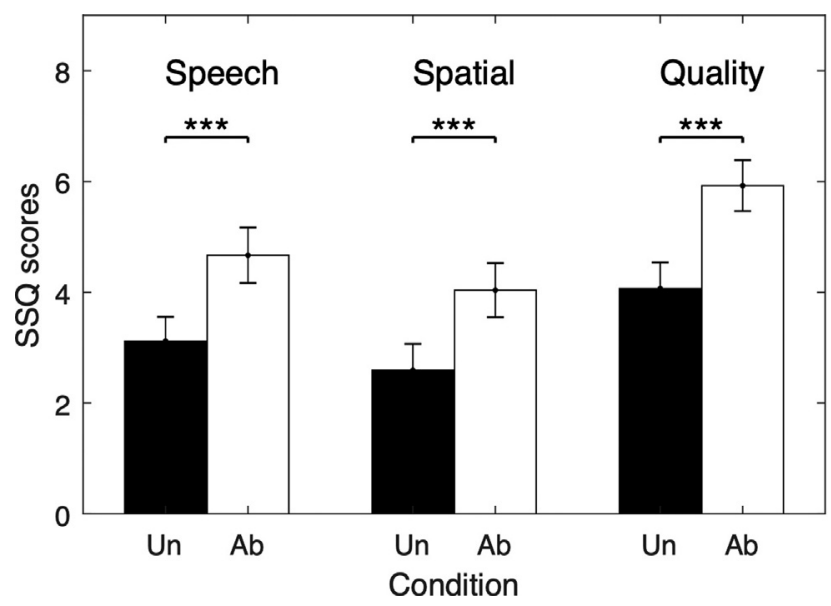

Fig. 4 Speech, Spatial and Qualities questionnaire mean scores ( $n=14$ patients), preoperatively (unaided, Un) versus postoperatively (abutment, Ab). Error bars depict the standard error of the mean. Significant differences between unaided and abutment are indicated by ${ }^{* * *}(p<0.0001)$.

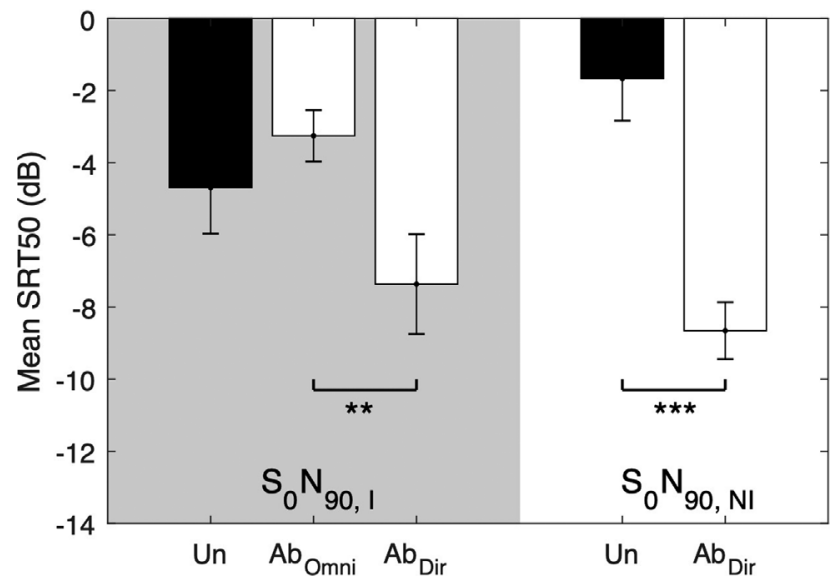

Fig. 5 Speech-in-noise performance, averaged across bilateral and unilateral patients $(n=9)$, in the unaided condition (Un) versus postoperatively (abutment, $A b$; in omnidirectional or directional settings). The two spatial configurations differ for the location of the noise, from either the implanted side (I, gray-shaded area) or nonimplanted side (NI). Error bars depict the standard error of the mean.

mean speech reception threshold at 50\% correct criterion (SRT50) for the unaided conditions (black bars) and the aided condition with the sound processor mounted on abutment (white bars). When the noise was located at the implanted side $\left(\mathrm{S}_{0} \mathrm{~N}_{90}, \mathrm{I}\right)$ and the patient was unaided, a SRT50 of $-4.7 \mathrm{~dB}$ was obtained. When the same spatial configuration was tested with the sound processor mounted on abutment, 
no significant difference in performance relative to the unaided condition was obtained (Unaided versus $\mathrm{Ab}_{\mathrm{Omni}}$ : $p=0.137$; Unaided versus $\left.A b_{\text {Dir }}: p=0.159\right)$. Although the noise was on the same side as the sound processor, and hence more noise was transmitted to the best cochlea ("worst-case scenario"), no worsening in performance was observed. The effect of directionality was significant $(p=0.008)$.

When the noise was located at the nonimplanted side $\left(\mathrm{S}_{0} \mathrm{~N}_{90}, \mathrm{NI}\right)$, a significant improvement in performance was observed with the sound processor on abutment condition relative to the unaided situation $(p=0.0002)$. A critical $p$-value of 0.0125 was used (Bonferroni correction by $n=4$ comparisons) to determine statistical significance.

\section{Surgical Outcomes}

The average duration of surgery with the linear incision technique was of 33.4 minutes (standard deviation: 8.4 minutes; min-max: 20-50 minutes); the average duration of surgery with MIPS was of 17 minutes (standard deviation: 2.7 minutes; min-max: 15-20 minutes). No intraoperative complications were reported. One postoperative complication (wound dehiscence) was reported for one patient (patient 4 , linear incision) at visit 4 , together with an adverse skin reaction (red and moist tissue, Holgers score $=2$ ). Both oral and local antibiotic treatments were provided for this patient. Additionally, the skin level for 2 patients (patients 1 and 4, linear incision) was reported to be above the shoulder of the abutment. For all the other patients, no postoperative complications were observed at any follow-up visit, no adverse skin reaction was registered at any follow-up visit (Holgers score $=0 ;-$ Table 4), and all skin levels were reported to be below the shoulder of the abutment. Implant survival was $100 \%$.

\section{Discussion}

Although the preoperative trial with softband is well-established and widely used, ${ }^{2}$ studies directly comparing the performance of BAHS on softband with unaided performance are scarce and mostly performed on children ${ }^{3,13,14}$ or young adults. $^{3,15}$ The present study showed that the aided soundfield thresholds obtained preoperatively in adult patients with the sound processor on softband are significantly improved relative to unaided performance at frequencies $<8 \mathrm{kHz}$. Postoperatively, significant improvements were obtained at all frequencies with the sound processor connected to the abutment (direct drive) relative to unaided performance. Importantly, the sound-field thresholds measured with the sound processor on abutment were significantly lower (better) than those on softband at all frequencies $>1 \mathrm{kHz}$. Hence, transmitting the vibrations directly to the skull bone without skin dampening (direct-drive ${ }^{4}$ ) led to significant improvements in sound transmission. This finding was further strengthened by the BC in-situ outcomes showing lower (better) thresholds with the sound processor connected to the abutment than with the softband. These findings show that even with advanced programmable sound processors fitted optimally on softband, transmission with skin-drive solutions is limited at mid to high frequencies. These results complement and corroborate previous findings, ${ }^{5}$ by showing that the benefit of percutaneous solutions relative to skin-drive solutions is already present at $750 \mathrm{~Hz}$ and extends at frequencies up to $8 \mathrm{kHz}$.

The outcomes of the SSQ questionnaire revealed a significant improvement in performance postoperatively with the sound processor connected to the abutment, relative to unaided. The average scores obtained for the aided condition were similar to the aided scores obtained in previous

Table 4 Surgical information and Holgers scores at follow-up visits

\begin{tabular}{|l|l|l|l|l|l|l|l|}
\hline Patient & $\begin{array}{l}\text { Implant } \\
\text { Length } \\
{[\mathrm{mm}]}\end{array}$ & $\begin{array}{l}\text { Abutment } \\
\text { Length } \\
{[\mathrm{mm}]}\end{array}$ & Incision technique & $\begin{array}{l}\text { Duration of surgery } \\
{[\mathrm{min}]}\end{array}$ & $\begin{array}{l}\text { Holgers } \\
\text { Visit 4 }\end{array}$ & $\begin{array}{l}\text { Holgers } \\
\text { Visit 5 }\end{array}$ & $\begin{array}{l}\text { Holgers } \\
\text { Visit 6 }\end{array}$ \\
\hline 1 & 4 & 9 & Linear & 35 & 0 & 0 & 0 \\
\hline 2 & 4 & 9 & Linear & 30 & 0 & 0 & 0 \\
\hline 3 & 4 & 9 & Linear & 50 & 0 & 0 & 0 \\
\hline 4 & 4 & 12 & Linear & 34 & 2 & 0 & 0 \\
\hline 5 & 4 & 6 & Linear & 40 & 0 & 0 & 0 \\
\hline 6 & 4 & 9 & Linear & 30 & 0 & 0 & 0 \\
\hline 7 & 4 & 6 & Linear & 40 & 0 & 0 & 0 \\
\hline 8 & 4 & 9 & Linear & 20 & 0 & 0 & 0 \\
\hline 9 & 4 & 9 & Linear & 30 & 0 & 0 & 0 \\
\hline 10 & 4 & 9 & MIPS & 20 & 0 & 0 & 0 \\
\hline 11 & 4 & 9 & MIPS & 20 & 0 & 0 & 0 \\
\hline 12 & 4 & 9 & MIPS & 15 & 0 & 0 & 0 \\
\hline 13 & 4 & 9 & MIPS & 15 & 0 & 0 & 0 \\
\hline 14 & 4 & 12 & MIPS & 20 & 0 & 0 & 0 \\
\hline
\end{tabular}

Abbreviation: MIPS, minimally invasive Ponto surgery. 
studies. ${ }^{16-19}$ The present study demonstrates a significant benefit of the percutaneous solution relative to the unaided condition across the three subscales (speech, spatial, quality of hearing), complementing the outcomes of a previous study, ${ }^{20}$ where no significant benefit was obtained in the quality of hearing subscale. A similar difference was previously reported in two studies. ${ }^{18,21}$ Interestingly, the results of the GHSI showed similar aided scores in the two patient groups, suggesting a similar perceived quality of life after implantation.

The speech-in-noise results showed that the aided performance in the "worst-case scenario," that is, when the noise was located at the side of the implant $\left(\mathrm{S}_{0} \mathrm{~N}_{90}\right.$, I $)$, was not worse than the unaided performance (where the listeners could benefit from the head-shadow effect). On the contrary, the aided performance in the "best-case scenario," that is, when the noise was located contralateral to the side of the implant $\left(\mathrm{S}_{0} \mathrm{~N}_{90}, \mathrm{NI}\right)$, improved significantly relative to unaided performance. Thus, these results provide further evidence that similar or better speech-in-noise performance can be achieved with the use of a percutaneous BAHS solution. Additionally, the use of directionality improved the aided performance in both spatial configurations.

\section{Conclusion}

The present study helps to improve evidence for both behavioral and self-reported improvements in performance postoperatively with a bone-anchored sound processor connected via abutment relative to unaided performance. In particular, the percutaneous BAHS solution led to improved sound-field thresholds at all frequencies and speech-in-noise performance (noise on the nonimplanted side), as well as improvements in quality of life and perceived performance in speech, spatial hearing, and sound quality. Further improvements with the sound processor on abutment were also obtained relative to the preoperative performance on softband, especially at mid to high frequencies. Patients should be informed on the improvements they can expect when proceeding to a percutaneous BAHS solution. However, further studies with larger population are needed to confirm the study results.

\section{Conflict of Interests}

The authors have no conflict of interests to declare

\section{Acknowledgments}

The present work was supported by Oticon Medical.

\section{References}

1 Tjellström A, Lindström J, Hallén O, Albrektsson T, Brånemark PI. Osseointegrated titanium implants in the temporal bone. A clinical study on bone-anchored hearing aids. Am J Otol 1981;2(04): 304-310

2 Zarowski AJ, Verstraeten N, Somers T, Riff D, Offeciers EF. Headbands, testbands and softbands in preoperative testing and application of bone-anchored devices in adults and children. Adv Otorhinolaryngol 2011;71:124-131
3 Wang Y, Fan X, Wang P, Fan Y, Chen X. Hearing improvement with softband and implanted bone-anchored hearing devices and modified implantation surgery in patients with bilateral microtia-atresia. Int J Pediatr Otorhinolaryngol 2018;104:120-125

4 Reinfeldt S, Håkansson B, Taghavi H, Eeg-Olofsson M. New developments in bone-conduction hearing implants: a review. Med Devices (Auckl) 2015;8:79-93

5 Verstraeten N, Zarowski AJ, Somers T, Riff D, Offeciers EF. Comparison of the audiologic results obtained with the bone-anchored hearing aid attached to the headband, the testband, and to the "snap" abutment. Otol Neurotol 2009;30(01):70-75

6 Håkansson B, Tjellström A, Rosenhall U. Hearing thresholds with direct bone conduction versus conventional bone conduction. Scand Audiol 1984;13(01):3-13

7 Lunner T, Rudner M, Rosenbom T, Ågren J, Ng EH. Using speech recall in hearing aid fitting and outcome evaluation under ecological test conditions. Ear Hear 2016;37(Suppl 1):145S-154S

8 Puglisi GE, Warzybok A, Hochmuth S, et al. An Italian matrix sentence test for the evaluation of speech intelligibility in noise. Int J Audiol 2015;54(Suppl 2):44-50

9 Robinson K, Gatehouse S, Browning GG. Measuring patient benefit from otorhinolaryngological surgery and therapy. Ann Otol Rhinol Laryngol 1996;105(06):415-422

10 Gatehouse S, Noble W. The speech, spatial and qualities of hearing scale (SSQ). Int J Audiol 2004;43(02):85-99

11 Holgers KM, Tjellström A, Bjursten LM, Erlandsson BE. Soft tissue reactions around percutaneous implants: a clinical study of soft tissue conditions around skin-penetrating titanium implants for bone-anchored hearing aids. Am J Otol 1988;9(01):56-59

12 Kuznetsova A, Brockhoff PB, Christensen RH. lmerTest package: tests in linear mixed effects models. J Stat Softw 2017;82(13): $1-26$

13 Hol MK, Cremers CW, Coppens-Schellekens W, Snik AF. The BAHA Softband. A new treatment for young children with bilateral congenital aural atresia. Int J Pediatr Otorhinolaryngol 2005;69 (07):973-980

14 Christensen L, Smith-Olinde L, Kimberlain J, Richter GT, Dornhoffer JL. Comparison of traditional bone-conduction hearing AIDS with the Baha system. J Am Acad Audiol 2010;21(04):267-273

15 Gawliczek T, Wimmer W, Munzinger F, Caversaccio M, Kompis M. Speech Understanding and Sound Localization with a New Nonimplantable Wearing Option for Baha. BioMed Res Int 2018; 2018:5264124

16 Kunst SJ, Hol MK, Mylanus EA, Leijendeckers JM, Snik AF, Cremers CW. Subjective benefit after BAHA system application in patients with congenital unilateral conductive hearing impairment. Otol Neurotol 2008;29(03):353-358

17 Dun CA, de Wolf MJ, Mylanus EA, Snik AF, Hol MK, Cremers CW. Bilateral bone-anchored hearing aid application in children: the Nijmegen experience from 1996 to 2008. Otol Neurotol 2010;31 (04):615-623

18 Hougaard DD, Boldsen SK, Jensen AM, Hansen S, Thomassen PC. A multicenter study on objective and subjective benefits with a transcutaneous bone-anchored hearing aid device: first Nordic results. Eur Arch Otorhinolaryngol 2017;274(08):3011-3019

19 Bosman AJ, Kruyt IJ, Mylanus EAM, Hol MKS, Snik AFM. Evaluation of an abutment-level superpower sound processor for boneanchored hearing. Clin Otolaryngol 2018;43(04):1019-1024

20 Nelissen RC, Mylanus EA, Cremers CW, Hol MK, Snik AF. Longterm compliance and satisfaction with percutaneous bone conduction devices in patients with congenital unilateral conductive hearing loss. Otol Neurotol 2015;36(05):826-833

21 Eberhard KE, Olsen SØ, Miyazaki H, Bille M, Caye-Thomasen P. Objective and subjective outcome of a new transcutaneous bone conduction hearing device: half-year follow-up of the first 12 Nordic implantations. Otol Neurotol 2016;37(03):267-275 